\title{
Out in left field? \\ A speculative viewpoint on the future
}

Alan Thomson MD

'Out in left field' - a baseball term suggesting that you (or your view points) are a little eccentric, unfashionable or just plain downright wrong! Perhaps a little akin to 'off the wall' or perhaps 'out to lunch' or any idea which is not up for nomination to be 'cool!' When is the clairvoyant really a soothsayer? When is the rebel really an eye to the future? When is the individual who is provocative and thoughtful a heretic to be burned at the stake, or an investor putting their life savings in that funny new company 'Microsoft', when most of us thought that a 'hard drive' was the commute home from downtown Toronto!

So please give me a little license to be bold, brash, daring and speculative about a glimmering glimpse of the possible future of gastroenterology. We have been a specialty for only 50 years, and we are still in evolution. What does the future of gastroenterology hold? With major advances toward gastroenterology in the broader perspective brought about by the enormous patient care success of liver transplantation, perhaps divisional organizational structures need to take into account the possibility of hepatology increasingly moving into a separate administrative group within academic medical centres. We will most likely all stay friends, the 'lumenologists' will likely maintain a basic level of skill in hepatology at least comparable with an up-to-date general internist, and the 'hepatologist' will likely maintain at least some endoscopic skill but perhaps lose the fine touch for the care of the subtleties of the patient with dyspepsia or inflammatory bowel disease (IBD) (yes, the IBD specialists will likely in time wish to have their own special group as well). But what makes us gastroenterologists is not only the knowledge base that we have to apply to the outstanding care of patients with gastrointestinal (GI) disorders, but it is also the endoscopic procedures that we use to make diagnoses, and in some instances, to treat our patients. Hepatologists are not as tightly wed to 'the scope' as lumenologists (I have not yet heard of a gastroenterologist who is actually a liver transplant surgeon), and so for some, gastroenterology is almost equivalent to being a thinking, well-read, informed, consultative endoscopist. What would happen to our specialty if the role of endoscopy should lessen?

Heaven forbid that you talk to some of the academic gastroenterology giants on whose shoulders we stand, to learn how in the earlier days gastroenterologists would do their own upper GI series. The very thought of a technician participating in this process was akin to the strength of the antibody response to some suggestions for innovative care in the current endoscopic era we know. What happens when one suggests that we thoughtfully review the evidence from British studies reporting the beneficial role of nurse practitioners doing colonoscopies?
What happened to the use of esophagogastroduodenoscopy for the care of patients with dyspepsia? With the widespread acceptance of the CanDys approach for patients younger than 50 years of age with dyspepsia and no alarm symptoms, some say one-third fewer esophagogastroduodenoscopies are being performed in patients with heartburn, regurgitation, nausea and fullness. The prevalence of missed gastric and esophageal cancer has not gone up, and family physicians now feel empowered to treat patients on an empirical basis (remember the early days of protein pump inhibitors when it was suggested that only gastroenterologists should use this powerful new class of medications, and even then only after a scope!). As we reflect upon how infrequently Barrett's epithelium progresses to esophageal cancer, whether the age cut-off for performing endoscopy in a dyspeptic patient should increase from 50 to 60 to 70 years or more, and analyze the sensitivity and specificity of so called 'alarm symptoms' (such as dysphagia, vomiting and weight loss), we might find that there is even less need for the endoscopic investigation of most patients with dyspepsia. Heaven forbid that the 'capsule' can be modified to allow for a quick view of the esophagus, stomach and duodenum before the voyage of discovery through the small intestine.

It was in only a few short years that diagnostic endoscopic retrograde cholangiopancreatographies were no longer being performed by individuals with only diagnostic and no therapeutic skills ('You can look, but you cannot cut'). Magnetic resonance cholangiopancreatographies may possibly replace endoscopic retrograde cholangiopancreatographies for diagnostic purposes. Now we are all excitedly deciding whether to train in capsule endoscopy. That technology may soon be obsolete with the coming of double balloon enteroscopy!

The big future turf war will likely come over stamping out colon cancer and the provision of colon cancer screening for the masses. Already we have young and not-so-young gastroenterologists who no longer want to take night or weekend calls. Who will actually do the very difficult, challenging work of caring for sick inpatients? How many of us will decide instead to work in very slick, efficiently run, ambulatory endoscopy units? That does not sound so bad after all, does it? Perhaps it is time to move all elective endoscopic procedures out of the hospitals. But what proportion of the lumenologist's time is spent doing colonoscopy? Fifty slots a week? Thirty? Twenty? Contemplate what would happen to the need for gastroenterology services in your community if only therapeutic colonoscopies needed to be performed. It is only a matter of time before ('virtual') computed tomography colonoscopy or magnetic resonance colonoscopy replace standard optical colonoscopy for screening purposes. The fecal DNA, messenger RNA and protein tests are becoming 
more sensitive and specific, and it is only a matter of time before an engineering genius will modify capsule endoscopy to allow for screening examinations of the large intestine or modify the software programs for computed tomography colonoscopy so that laxative preparations are not needed.

What will all the underemployed colon cancer screening lumenologists do then? What we will do is return to being more like the hepatologists, talking about patient issues rather than spending so much of our time in the endoscopy room. Of course we will continue to miraculously stop GI bleeding, prevent varices from bleeding or rebleeding and we will continue to improve the quality of life for sufferers of IBD. We will become more like the internists from whom we have evolved over the past 50 years - we will become a subspecialty once again founded on the basis of the type of patients we care for and our knowledge and consultative excellence, rather than our procedural skills.

With the evolution toward more and more subspecialization, there developed the 'GI ward'. The concept was simple only gastroenterologists know the best way to look after patients with gastroenterology problems. Sounds simple. So why have so many academic medical centres now moved away from the GI ward concept, having patients cared for by general internists, and where appropriate, a patient having a gastroenterology consultation? Some would argue that because there is such a shortage of gastroenterologists, freeing them from ward responsibilities may help to concentrate their efforts in other areas. But in many institutions there is a critical shortage of generalists. In practice, why is the GI ward a faulty concept? If the typical patient with an upper GI bleeding was a 30-year-old with a bleeding duodenal ulcer, then he/she would have an urgent endoscopy, the lesion would be injected/cauterized/clipped and the patient would quickly go home. Hurray! But the typical patient with an upper GI bleeding is approximately 75 years of age, with seven associated medical problems. To fix the bleeding ulcer is relatively easy. What is not always easy is for the highly specialized gastroenterologist, who has been away from general internal medicine (GIM) for many years, to effectively and efficiently look after all of the other comorbid conditions. Somehow it makes more sense for the general internist to admit and care for all patients, with the gastroenterology service quickly being consulted to help in looking after the bleeding ulcer, while the GIM specialist looks after the patient. It is not that we are not interested in the patient, it is just that our skills as general internists may be a little rusty.

Of course, some gastroenterologists have maintained a high level of skill and expertise in GIM, usually because of the nature of their appointment in a hospital requiring them to continue to maintain GIM skills that were so carefully honed, polished and proven at the time of their earlier training. For most of us, we no longer understand the subtleties of which bronchodilator to use, which is the best calcium channel blocker and how best to titrate insulin administration to blood sugar levels in a patient with diabetic ketoacidosis, nor should we necessarily know this. We have been developing into highly qualified experts, understanding every subtle nuance of the art in the care of a patient with IBD or hepatitis $\mathrm{C}$ viral infection.

But this is all theory. What we need is carefully constructed studies examining reasonable clinical outcomes for patients with GI disorders who are randomly assigned under the care of a gastroenterology team versus a GIM team. Let us get the data to see if there might be a better way to utilize our resources.

Once again, hepatologists are leading the way, bringing back a concept that for years has been alive and well in many other GIM specialties, the concept of 'the team'. The liver transplant team will have surgeons, pathologists, internists, pharmacists, psychiatrists, social workers, physiotherapy and ethicists. Slowly, the team concept in lumenology is beginning to appear; for example, the team approach to the care of the patient with IBD. Perhaps the GI ward of the future will be very different with patients cared for by internists who readily consult when the need arises. We already have that in some institutions with a 'liver' patient cared for by the 'general gastroenterologist' (the 'lumenologist'!), and the hepatologist consulting on a frequent and often daily basis. But of course, until we have data, we do not know whether this is the best approach, so let us go out and get the data!

Are these reflections and musings of a future really 'out in left field?' Is every baby in this country delivered by an obstetrician or is perinatal care adequately provided for most expectant mothers by midwives or a family practitioner? When was the last time you saw a patient who was recently treated with an open cholecystectomy? How many surgeons in your institution could you find who remain skilled at doing a Billroth II gastric resection? And how many of you have actually heard of, let alone used, a Sippy diet? Our specialty is in evolution. We do not need a study to tell us that there is a manpower shortage (oops! pardon me ladies, - a human resource shortage), although certainly having data is useful evidence to be used for governmental decisions. But will the government happily continue to provide funds to train more and more and more highly qualified gastroenterologists who go out and break the health care budget with their high level of billings - all of which are justified, appropriate and reasonable, unless you are paying the bill? So we need to work within whatever groups we choose (Canadian Association of Gastroenterology, Canadian Association for the Study of the Liver or the Ontario Society of Gastroenterology), and other groups that we may not necessarily choose (government and insurance companies, to name a few).

Perhaps it is time for a paradigm shift ("a break from the constraints of existing thought that then allows the individual to see the composite picture in another way"; [Gastroenterology $2005 ; 1-8: 1771-2])$, in which a gastroenterologist moves from doing everything for the patient's GI disorder, to consulting on the GI aspect of the patient with many associated medical conditions. Some would suggest that we will become superspecialized as experts, in IBD, motility and not just hepatology but transplant hepatology, primary biliary cirrhosis or one of the infectious hepatitis viruses. Perhaps some of us will evolve back into being more general and others even more specialized.

Far fetched? It was not that long ago that it was unthinkable that our country might be split in two by a $0.1 \%$ referendum margin, that we might extend social equality to those of different sexual orientations or that we might be forced to look for alternate ways to provide health care through innovation and experimentation. The future is yours, is ours. Let us not be so wrapped up in what we do today or in the next week, month or year(s), that we fail to notice what is happening around us. Let us not fail to remember what happened to another previous Albertan, the dinosaur! 


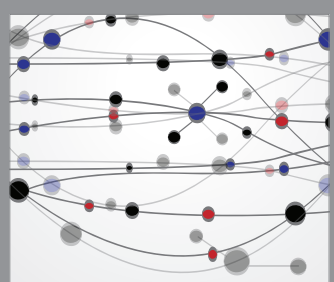

The Scientific World Journal
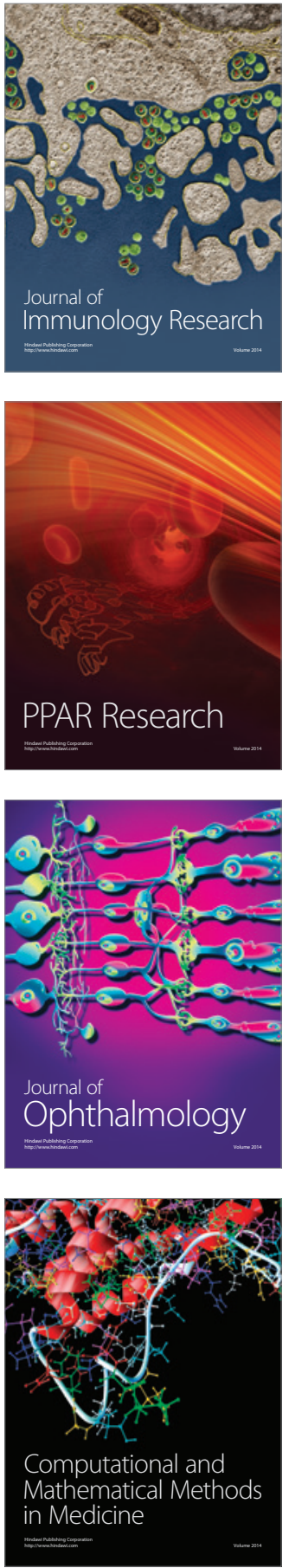

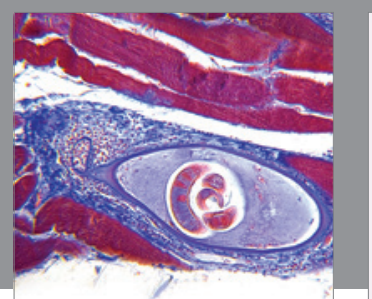

Gastroenterology Research and Practice

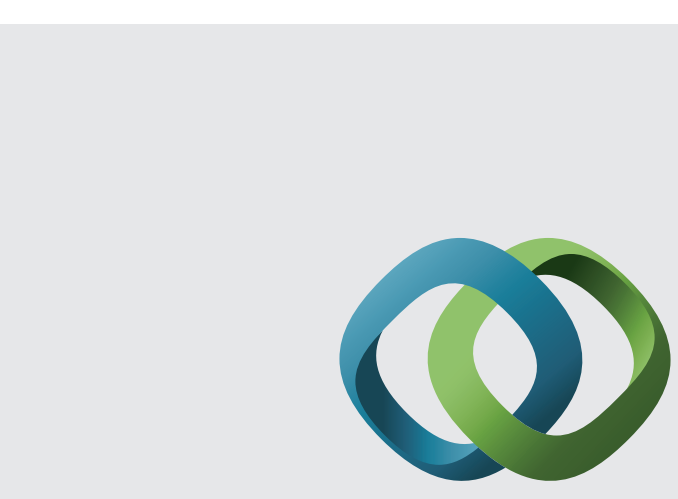

\section{Hindawi}

Submit your manuscripts at

http://www.hindawi.com
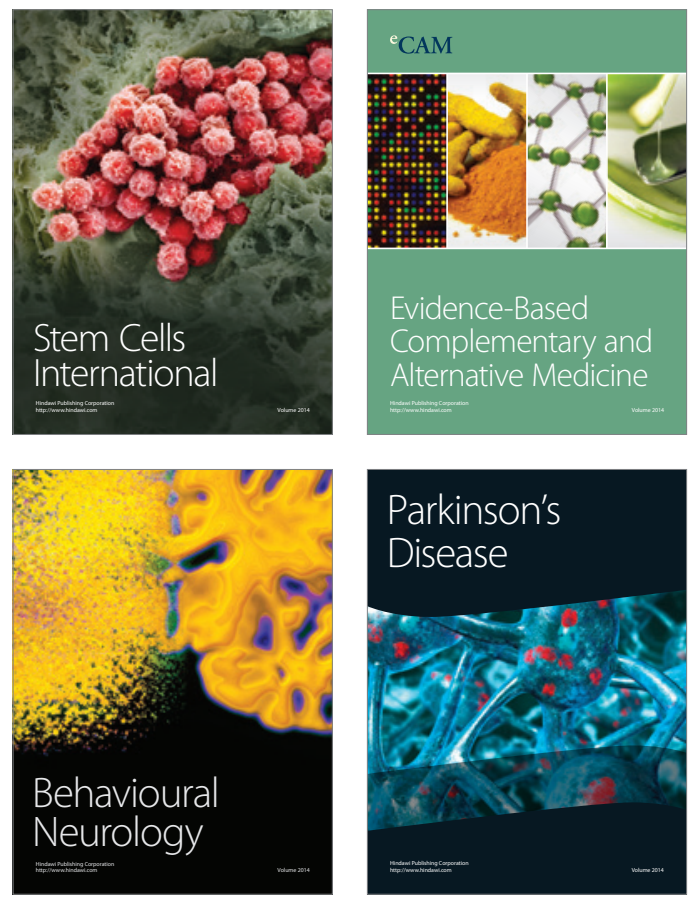
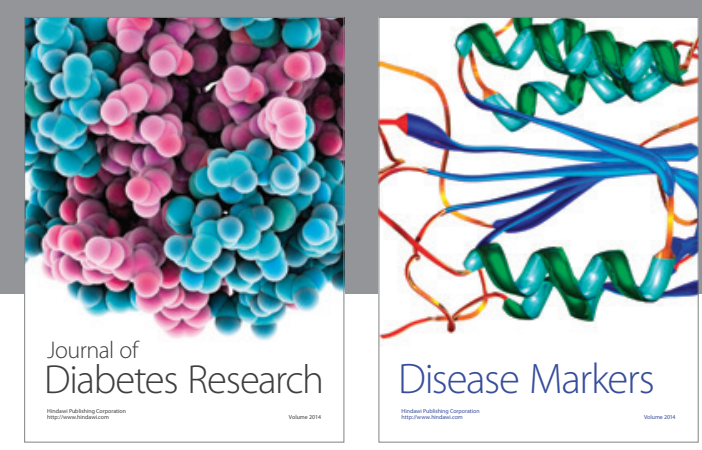

Disease Markers
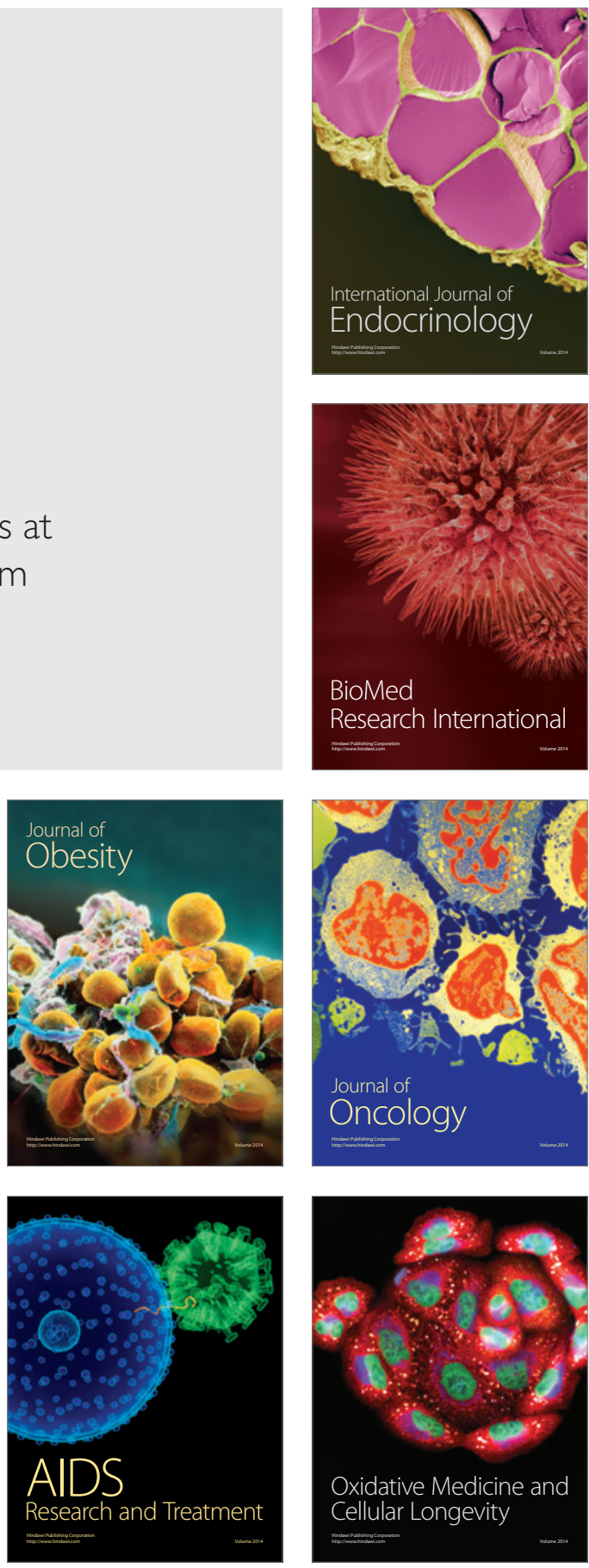